\title{
Successful Deferasirox Rechallenge and Treating Through Reaction in a Patient with Challenge-Proven Mild Immediate Reaction: A Case Report
}

This article was published in the following Dove Press journal: Journal of Asthma and Allergy

Mongkhon

Sompornrattanaphan (D) $^{\prime}$

Thanachit Krikeerati ${ }^{1,2}$

Chamard Wongsa (D)

Torpong Thongngarm (1)

Kittika Yampayon (1D) ${ }^{3}$

'Division of Allergy and Clinical Immunology, Department of Medicine, Faculty of Medicine, Siriraj Hospital, Mahidol University, Bangkok, Thailand; ${ }^{2}$ Department of Medicine, Faculty of Medicine, Khon Kaen University, Khon Kaen, Thailand; ${ }^{3}$ Adverse Drug Reaction (ADR) Unit, Pharmacy Department, Siriraj Hospital, Mahidol University, Bangkok, Thailand
Correspondence: Kittika Yampayon Adverse Drug Reaction (ADR) Unit, Pharmacy Department, Siriraj Hospital, Mahidol University, 2 Wanglang Road, Bangkok Noi, Bangkok 10700, Thailand

Tel +66814886887

Fax +6624197376

Email kittika.yampayon@gmail.com

\begin{abstract}
This is the first report of successful deferasirox administration, using graded challenge and treating through, in a patient with mild immediate hypersensitivity reaction. Beginning with drug graded challenges could indicate the eliciting dose and reaction severity which are important for the management plan in the next step. This approach could be a safe shortcut in a stable patient with a mild reaction and a long avoidance period.
\end{abstract}

Keywords: deferasirox, drug allergy, rechallenge, desensitization, hypersensitivity, iron overload, iron chelating agents, thalassemia, premedication

\section{Introduction}

There are three iron-chelating agents for patients with transfusion-dependent thalassemia, including deferoxamine (DFO), deferiprone (DFP), and deferasirox (DFX). There is a significant variation in the recommendations for iron chelation therapy. ${ }^{1-3}$ DFX dose of $30-40 \mathrm{mg} / \mathrm{kg} /$ day could reduce serum ferritin level, liver iron concentration (LIC), and achieved negative iron balance in transfusiondependent thalassemia. DFX is well tolerated in most patients. Longer-term extension studies have confirmed the efficacy and safety of DFX. ${ }^{4}$

The most common adverse events consist of gastrointestinal disturbances, skin rash, nonprogressive increases in serum creatinine, and elevations in liver enzyme levels. DFX is known to cause a maculopapular eruption in up to $10 \%$ of the patients. There were reports regarding successful DFX desensitization for delayed-type drug hypersensitivity reactions (DHR), including maculopapular eruption and erythema multiforme. ${ }^{5,6}$ Those protocols took several days to achieve the target dose. There have been no reports on a challenge-proven immediate hypersensitivity reaction. Therefore, we report a case of challenge-proven immediate hypersensitivity reaction and successful DFX graded challenge with treating through the reaction.

\section{Case Presentation}

A 50-year-old woman with $\beta$-thalassemia/ $\mathrm{Hb} \mathrm{E}$ and secondary hemochromatosis due to blood transfusion since the age of eight. She was initially prescribed oral DFP for the treatment of iron overload, but she developed DFP-induced agranulocytosis, leading to drug discontinuation. After 2 months, her white blood cell count returned to normal range. DFX was prescribed as an alternative for iron chelation in May 2006. Three hours after taking $1000 \mathrm{mg}$ of DFX, she had a generalized pruritic 


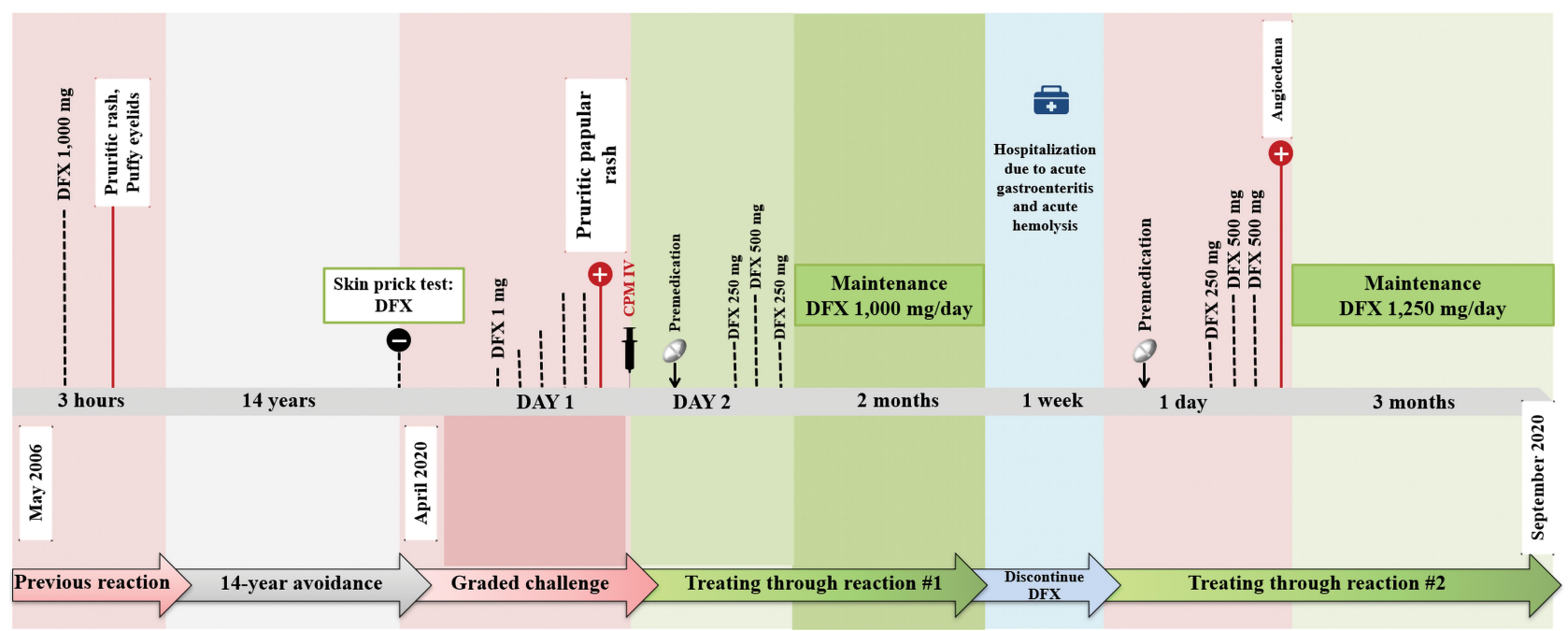

Figure I The timeline of the case report.

Abbreviations: CPM IV, intravenous chlorpheniramine; DFX, deferasirox; mg, milligram.

rash and swollen eyelids. The hematologist discontinued the drug and prescribed H1-antihistamine with prednisolone, $20 \mathrm{mg} /$ day, for 3 days. The rash was completely resolved without hyperpigmentation within 1 day. Subcutaneous injection of DFO was then used as the single ironchelating agent from the years 2006 to 2019. However, the serum ferritin level was still excessive, ranging from 1300 to $2000 \mathrm{ng} / \mathrm{mL}$. Magnetic resonance imaging revealed $\mathrm{T} 2 *$ heart $=48.6 \mathrm{~ms}$ which is within the normal range (normal Cardiac T2* >25 ms; In case of iron overload, mild $=20-25 \mathrm{~ms}$, moderate $=10-20 \mathrm{~ms}$, and severe $\leq 10$ $\mathrm{ms}$ ). She had liver iron concentration (LIC) of $35.1 \mathrm{mg}$ of elemental iron $/ \mathrm{g} \mathrm{dw}$, which indicated severe liver iron overload (LIC $\leq 3$ = normal, 3-7 = mild, 7-15 = moderate, and $>15=$ severe iron overload). She had persistent transaminitis (ALT, ranging $80-90 \mu \mathrm{g} / \mathrm{L}$ and AST, ranging 100-150 $\mu \mathrm{g} / \mathrm{L}$ ), and a mean liver stiffness value of 7.7 kilopascals indicated by fibroscan. Left and right ventricular ejection fractions were $69.4 \%$ and $59.4 \%$, respectively. No valvular heart diseases were demonstrated.

The patient was referred to allergy consultation due to the need for DFX use in April 2020. As DFX in solution form was not available, we initially performed DFX skin prick test (SPT) by dissolving 500-mg tablet of DFX in $25 \mathrm{~mL}$ of $0.9 \%$ saline at room temperature for 20 minutes, giving a $20 \mathrm{mg} /$ $\mathrm{mL}$ concentration. The SPT result was negative.

The overall timeline is summarized in Figure 1. We performed DFX graded challenge to confirm the diagnosis and indicated the eliciting dose under close monitoring (Table 1). DFX challenge started with $1 \mathrm{mg}$, followed by $10 \mathrm{mg}, 100 \mathrm{mg}, 250 \mathrm{mg}, 250 \mathrm{mg}$ with escalation at every 1-hour interval. Generalized pruritic papular rash (Ring

Table I DFX Graded Challenge and Treating Through Protocol in Our Case

\begin{tabular}{|c|c|c|c|c|c|}
\hline \multicolumn{2}{|c|}{ DFX Graded Challenge } & \multirow{2}{*}{\multicolumn{2}{|c|}{$\begin{array}{l}\text { Ist Graded Challenge and Treating } \\
\text { Through Reaction (April 2020) } \\
\text { Premedication: Bilastine } 40 \mathrm{mg} / \text { Day }\end{array}$}} & \multirow{2}{*}{\multicolumn{2}{|c|}{$\begin{array}{l}\text { 2nd DFX Graded Challenge and Treating } \\
\text { Through Reaction (June 2020) } \\
\text { Premedication: Bilastine } 40 \mathrm{mg} / \text { Day }\end{array}$}} \\
\hline Time (Hour) & DFX Dose (mg) & & & & \\
\hline 0 & I & Time (hour) & DFX dose (mg) & Time (Hour) & DFX Dose (mg) \\
\hline I & 10 & 0 & 250 & 0 & 250 \\
\hline 2 & 100 & 2 & 500 & 2 & 500 \\
\hline 3 & 250 & 4 & 250 & 4 & 500 \\
\hline 4 & 250 & & & & \\
\hline \multicolumn{2}{|c|}{$\begin{array}{l}\text { Positive reaction (Generalized pruritic papules at } \\
\text { the extremities and trunk) }\end{array}$} & \multicolumn{2}{|c|}{$\begin{array}{l}\text { No breakthrough reactions after the last } \\
\text { dose (3-hour observation) }\end{array}$} & \multicolumn{2}{|c|}{$\begin{array}{l}\text { Breakthrough reaction: Mild lip angioedema at } 2 \\
\text { hours }\end{array}$} \\
\hline
\end{tabular}

Abbreviations: DFX, deferasirox; mg, milligram. 


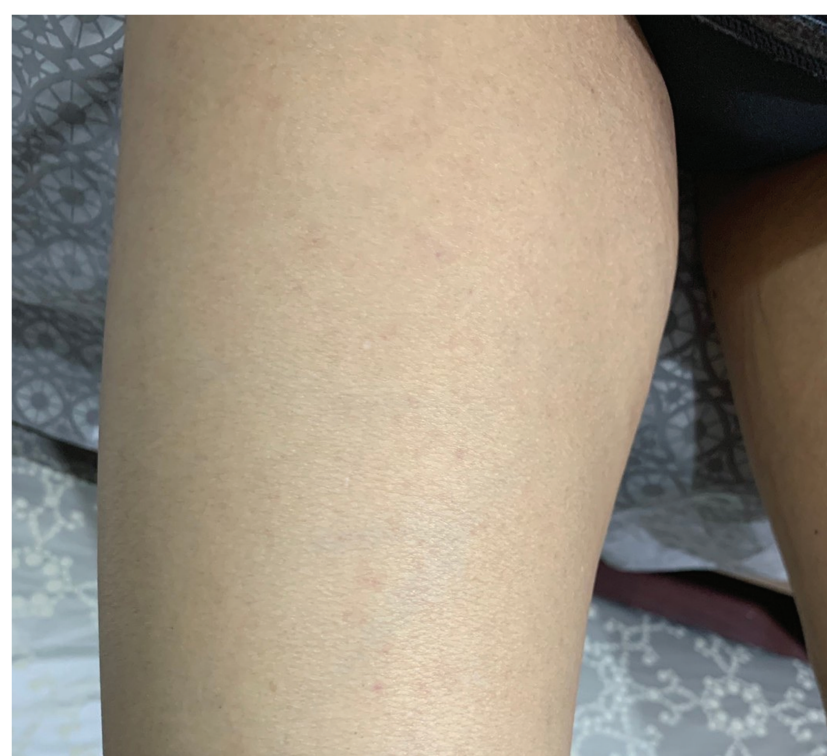

Figure 2 Positive DFX challenge: a few discrete ill-defined erythematous macules on the right arm.

and Messmer grade 1) occurred at the cumulative dose of $611 \mathrm{mg}$ (Figure 2). We treated the reaction with intravenous chlorpheniramine and started bilastine $20 \mathrm{mg}$ twice daily for premedication purposes. After the rash was resolved, we restarted the graded challenge on the next day, starting with $250 \mathrm{mg}$, followed by $500 \mathrm{mg}$, and $250 \mathrm{mg}$. A cumulative dose of $1000 \mathrm{mg} /$ day of DFX was achieved without a breakthrough reaction. Because the elimination half-life of DFX was $8-16$ hours, $^{7}$ the patient then was advised to take the drug $500 \mathrm{mg}$ twice daily to ensure DFX remained in the body at all times to cover the medication interval as well as to reduced plasma drug level fluctuations and gastrointestinal side effects. ${ }^{8,9}$ Bilastine was discontinued 1 week later.

Two months later, she was admitted to a local hospital due to acute gastroenteritis with acute hemolysis. The physician discontinued DFX during the investigation. Red cell transfusion was administered. She was discharged without taking DFX for 1 week. An allergist was consulted for repeating DFX desensitization. A hematologist requested increasing the dose of DFX to $1250 \mathrm{mg}$. We premedicated with bilastine $20 \mathrm{mg} 1$ day before desensitization and continued twice daily. DFX desensitization was performed, starting with $250 \mathrm{mg}$, followed by $500 \mathrm{mg}$, and $500 \mathrm{mg}$. She developed mild lip angioedema 45 minutes after the last dose (Figure 3), which spontaneously resolved the next day without increasing the dose of antihistamine. She then continued a combination of iron-chelating agents

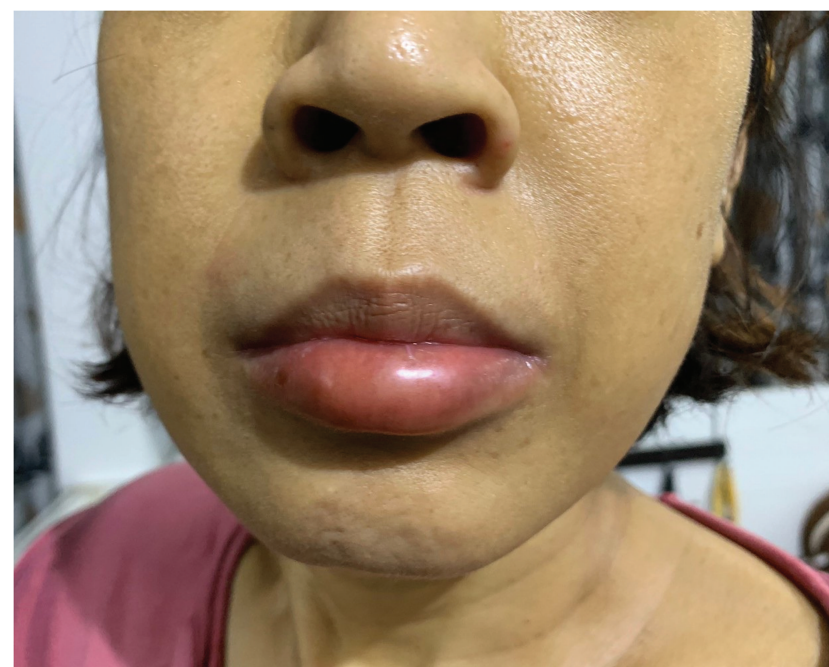

Figure 3 Lip angioedema during the second DFX graded challenge and treating through with $\mathrm{HI}$-antihistamine.

which included $1250 \mathrm{mg} /$ day of DFX, and subcutaneous DFO $3000 \mathrm{mg} /$ day, 4 times/week. She has finally achieved a desensitized state as she could discontinue antihistamine and continued DFX without any significant breakthrough reactions for the next 2 months. However, she developed a single episode of mild eyelid angioedema without visual disturbance after missing the DFX for 1 day. The reaction was resolved after taking oral bilastine $20 \mathrm{mg} /$ day for 3 days. At a 3-month follow-up visit in September 2020, her ferritin level was decreased to $601 \mathrm{ng} / \mathrm{mL}$. The liver enzymes were improved from baseline (ALT $44 \mu \mathrm{g} / \mathrm{L}$ and AST $56 \mu \mathrm{g} / \mathrm{L}$ ). The serum creatinine was $0.64 \mathrm{mg} / \mathrm{dL}$. No significant impairment of the patient's hearing and vision during the 3-month follow-up. The patient has been continuing on DFX until now (September 2020).

\section{Discussion}

This is the first report of challenge-proven DFX-induced immediate hypersensitivity reaction. There is a tendency for the drug-specific IgE level to decline over time and the observation of tolerance developing in patients with IgE-mediated reactions. ${ }^{10,11}$ Therefore, we initially performed a graded challenge to confirm the diagnosis as some patients might develop natural tolerance after a long avoidance period. This approach could indicate the eliciting dose and the appropriate interval for designing a graded challenge/desensitization protocol. A general published desensitization protocol begins with a $1 /$ 10,000 dose, which would sometimes take a longer time to reach the target dose. 
We observed that the majority of patients who underwent chemotherapy desensitization usually elicited breakthrough reactions in the terminal step at high doses. ${ }^{12}$ This implied that the eliciting dose threshold of each patient was varied. We believed that graded challenge/desensitization could be individually tailor-made and might not necessarily start at a very low dose in all cases, especially those with mild reaction and long avoidance period since the last reaction. Our patient had a high eliciting dose, $>50 \%$ of therapeutic dose, demonstrated by the first graded challenge and the reaction was non-anaphylaxis. She had no risk of severe reactions, such as decompensated cardiopulmonary diseases or taking antihypertensive medications. Treating through the reaction with H1-antihistamine during graded challenges could be an alternative option in such a case. As she had recurrent reactions from DFX reexposure after short discontinuation, this was compatible with the traditional definition of desensitization, the temporary induction of tolerance.

\section{Conclusion}

In conclusion, we report the first case of challenge-proven immediate hypersensitivity reaction to DFX and performed graded challenge with treating through the reactions using H1-antihistamine. The patient finally developed tolerance to the drug as the patient could discontinue H1-antihistamine. We provide a new perspective that "not all individuals with immediate reaction require desensitization starting at a very low dose with multiple steps". However, the decision should be based on the patient's status, history of index reaction, the eliciting dose, and the patient's informed consent.

\section{Ethical Approval}

The institutional approval was not applicable (case report).

\section{Consent for Publication}

Written informed consent for publication was obtained from the patient. The patient was informed that deidentified data would be used in scientific research and publications.

\section{Acknowledgment}

We acknowledge the contributions of Ms Orathai Theankeaw and Ms Aree Jameekornrak Taweechue for the research assistance. We also thank Dr Anthony Tan for editing the English language in the manuscript.

\section{Authorship}

All authors made a significant contribution to the work reported, whether that is in the conception, execution, acquisition of data, analysis, and interpretation, or in all these areas; took part in drafting, revising, or critically reviewing the manuscript; gave final approval of the version to be published; have agreed on the journal to which the article has been submitted; and agreed to be accountable for all aspects of the work.

\section{Funding}

There is no funding to report.

\section{Disclosure}

All authors declare no personal, professional, or other conflicts of interest.

\section{References}

1. Musallam KM, Angastiniotis M, Eleftheriou A, Porter JB. Cross-talk between available guidelines for the management of patients with beta-thalassemia major. Acta Haematol. 2013;130(2):64-73. doi:10. $1159 / 000345734$

2. Huang V, Luini C, El-Ali A, Kessabi S. Iron chelation therapy: a review of the literature on the issues and importance of adherence to treatment in iron overload. Blood. 2015;126(23):4748. doi:10.1182/blood.V126.23.4748.4748

3. Kontoghiorghe CN, Kontoghiorghes GJ. Efficacy and safety of iron-chelation therapy with deferoxamine, deferiprone, and deferasirox for the treatment of iron-loaded patients with non-transfusiondependent thalassemia syndromes. Drug Des Devel Ther. 2016;10:465-481. doi:10.2147/DDDT.S79458

4. Chaudhary P, Pullarkat V. Deferasirox: appraisal of safety and efficacy in long-term therapy. J Blood Med. 2013;4:101-110.

5. Bruner KE, White KM. Deferasirox desensitization. J Allergy Clin Immunol Pract. 2016;4(1):171-172. doi:10.1016/j.jaip.2015.09.007

6. Davies GI, Davies D, Charles S, Barnes SL, Bowden D. Successful desensitization to deferasirox in a paediatric patient with beta-thalassaemia major. Pediatr Allergy Immunol. 2017;28(2): 199-201. doi:10.1111/pai.12677

7. Tanaka C. Clinical pharmacology of deferasirox. Clin Pharmacokinet. 2014;53(8):679-694. doi:10.1007/s40262-014-0151-4

8. Lu MY, Wang N, Wu WH, et al. Simultaneous determination of plasma deferasirox and deferasirox-iron complex using an HPLC-UV system and pharmacokinetics of deferasirox in patients with beta-thalassemia major: once-daily versus twice-daily administration. Clin Ther. 2015;37 (8):1751-1760. doi:10.1016/j.clinthera.2015.05.506

9. Chang HH, Lu MY, Liao YM, et al. Improved efficacy and tolerability of oral deferasirox by twice-daily dosing for patients with transfusion-dependent beta-thalassemia. Pediatr Blood Cancer. 2011;56(3):420-424. doi:10.1002/pbc.22826

10. Isik P, Yarali N, Bay A, Ozmen S, Tunc B. Type-I hypersensitivity reaction secondary to deferasirox intake. Int $\mathrm{J}$ Hematol Oncol. 2010;20:42-44.

11. Blanca M, Torres MJ, Garcia JJ, et al. Natural evolution of skin test sensitivity in patients allergic to beta-lactam antibiotics. $J$ Allergy Clin Immunol. 1999;103(5):918-924. doi:10.1016/S0091-6749(99)70439-2

12. Kang Y, Kwon OY, Jung H, et al. Breakthrough reactions during rapid drug desensitization: clinical outcome and risk factors. Ann Allergy Asthma Immunol. 2019;123(1):48-56 e41. doi:10.1016/j. anai.2019.05.007 


\section{Publish your work in this journal}

The Journal of Asthma and Allergy is an international, peer-reviewed open-access journal publishing original research, reports, editorials and commentaries on the following topics: Asthma; Pulmonary physiology; Asthma related clinical health; Clinical immunology and the immunological basis of disease; Pharmacological interventions and

Submit your manuscript here: https://www.dovepress.com/journal-of-asthma-and-allergy-journal new therapies. The manuscript management system is completely online and includes a very quick and fair peer-review system, which is all easy to use. Visit http://www.dovepress.com/testimonials.php to read real quotes from published authors. 